J. of the Korean Sensors Society

Vol. 19, No. 6 (2010) pp. $421-427$

DOI : $10.5369 /$ JSST.2010.19.6.421

pISSN 1225-5475/eISSN 2093-7563

\title{
Alizarin Red S modified electrochemical sensors for the detection of aluminum ion
}

\author{
Seung-Cheol Chang
}

\begin{abstract}
Alizarin Red S modified screen printed carbon electrodes were developed for the electrochemical detection of aluminum ion. The electrodes developed use screen-printed carbon electrodes(SPCEs) coupled with chemical modification with an organic chelator, Alizarin Red S(ARS), for aluminum ion detection in aqueous solution. For sensor fabrication ARS was directly immobilized on the surface of SPCEs using PVA-SbQ(The poly(vinyl alcohol) bearing stryrylpyridinium groups). Aluminum concentrations were indirectly estimated by amperometric determination of the non-complexed ARS immobilized on the electrodes, after its complexation with aluminum. The sensitivity of the sensor developed was $3.8 \mathrm{nA \mu M}^{-1} \mathrm{~cm}^{-2}$ and the detection limit for aluminum was $25 \mu \mathrm{M}$.
\end{abstract}

Key Words : screen printed electrode, electrochemical, alizarin red S, aluminum ion

\section{Introduction}

Direct determination of aluminum(Al(III)) ions by voltammetric and amperometric methods using solid electrodes is limited for application to real samples because of a low signal-to-noise ratio ${ }^{[1]}$ and high reduction potential of $\mathrm{Al}(\mathrm{III})^{[2]}$. These limitations could be overcome by using indirect methods based on the electrodes modified with metal chelators such as Alizarin Red $\mathrm{S}^{[3-6]}$. These methods are based upon the measurement of changes in the electrochemical behavior of the chelator upon complexation with the $\mathrm{Al}(\mathrm{III})$.

Chemically modified electrodes(CMEs $)^{[10]}$ have been widely used for the electrochemical determination of metals in water resources ${ }^{[7]}$. CMEs, generally, have been used in voltammetric methods especially in anodic stripping voltammetry(ASV) with an analyte accumulation step. The modifiers, chelators, are physically or chemically modified onto the working electrode and used to accumulate the analyte followed by the indirect determination of the analyte. The reagents used for chemical modification of the electrode surface therefore fall into two main categories; accumulating reagents

Institute for Bio Physio Sensor Technology(IBST), Pusan National University

Corresponding author: s.c.chang@pusan.ac.kr

(Received: October 20, 2010, Revised: November 5, 2010, Accepted : November 10, 2010) and electro-active reagents. The use of CMEs in electrochemical analysis has led to the development of sensors exhibiting high selectivity and sensitivity for $\mathrm{Al}$ (III) ion in environmental water samples.

The work reported in this study is aimed at developing a rapid, sensitive and specific technique for the measurement of $\mathrm{Al}(\mathrm{III})$. The technique involved the use of an organic chelator, Alizarin Red S(ARS), modified disposable screen-printed carbon electrodes for the electrochemical determination of $\mathrm{Al}(\mathrm{III})$ ion in aqueous samples.

To achieve the aim proposed, this study was focused in two major areas. Firstly, the differences in electrochemical behavior between modified ARS and its complexed form with $\mathrm{Al}(\mathrm{III})$ was characterized and optimized using voltammetric and amperometric techniques. Secondly, disposable printed electrodes modified with immobilized ARS using the photo-polymer, PVA-SbQ ${ }^{[8,9]}$, for amperometric Al(III) detection was fabricated and tested.

\section{Experimental}

\subsection{Materials}

The basic disposable screen-printed carbon electrodes (SPCEs) were constructed as reported by author previously ${ }^{[8]}$. Alizarin Red S(ARS, 3.4-dihydroxy-9,10- 
dioxo-2-anthracensulfonic acid, sodium salt), aluminum nitrate $\left(\mathrm{Al}\left(\mathrm{NO}_{3}\right)_{3}\right)$, potassium chloride $(\mathrm{KCl})$, and potassium phosphates $\left(\mathrm{KH}_{2} \mathrm{PO}_{4}, \mathrm{~K}_{2} \mathrm{HPO}_{4}\right)$ were obtained from Sigma. The poly(vinyl alcohol) bearing stryrylpyridinium groups(PVA-SbQ) matrix(SPP-H-13) was from Toyo Gosei Kogyo Co.(Tokyo, Japan).

\subsection{Apparatus}

Cyclic voltammetry and amperometric measurements were performed using an Autolab analyzer supplied by Eco Chemie B.V.(Utrecht, Netherlands). A Perspex 10well template for accommodation of the screen-printed electrodes was built by the Workshop at Pusan National University. A Spectroline ${ }^{\mathbb{R}}$ UV lamp was obtained from Spectronics Co.(New York, USA) and was used for PVA-SbQ photo-polymerisation. $\mathrm{pH}$ measurement was performed using an Orion $\mathrm{pH}$ meter model 310 in conjunction with a PerpHecT $^{\circledR} \mathrm{Ag} / \mathrm{AgCl} \mathrm{pH}$ electrode model 9202 supplied by Orion ${ }^{\circledR}$ Research Inc.(Beverly, USA).

\subsection{Alizarin Red S(ARS) Solution}

$55 \mathrm{mM}$ Alizarin Red S(ARS) solution was prepared by dissolving $20 \mathrm{mg}$ of ARS in $20 \mathrm{ml}$ of $50 \mathrm{mM}$ potassium phosphate buffer(PPB, pH 7.0, $100 \mathrm{mM} \mathrm{KCl}) .2 \mathrm{ml}$ aliquots of ARS solutions were also prepared in the same buffer, over the concentration range of $0.5 \mathrm{mM} \sim$ $55 \mathrm{mM}$.

\subsection{Assessment of ARS Modified SPCEs(PVA-} SbQ(ARS)-SPCEs)

ARS was modified in the photo-polymer(PVA-SbQ) layer on the surface of the working electrodes. A $200 \mu \mathrm{l}$ aliquot of $55 \mathrm{mM}$ ARS solution was thoroughly mixed with $300 \mu \mathrm{l}$ of PVA-SbQ prepolymer for 5 minutes. A $5 \mu \mathrm{l}$ aliquot of the mixture was placed on the surface of the working electrode of the SPCEs. The electrodes were then exposed to long wave UV $\operatorname{light}(365 \mathrm{~nm}$, at $10 \mathrm{~cm}$ ) for $2 \mathrm{~h}$ to allow polymerization, and dried in a dark place for $12 \mathrm{~h}$ at room temperature. $40 \mu \mathrm{mol}$ of ARS was modified on each SPCE. In order to investigate the voltammetric behavior of ARS in PPB, PVASbQ(ARS)-SPCEs were also prepared using the $2 \mathrm{ml}$ aliquots of ARS solutions as described in Section 2.3.

\subsection{Measurement Procedure}

An electrochemical cell for voltammetric and amper- ometric measurements was set up and Cyclic voltammetry was carried out using polymer coated bare SPCEs and PVA-SbQ(ARS)-SPCEs and were used according to the procedure outlined in previous studies by author ${ }^{[8,9]}$. Experimental protocols were identical except for the following conditions; $50 \mathrm{mM}$ PPB was used as background electrolyte and the potential sweeping range was between $-0.1 \mathrm{mV}$ to $+1.0 \mathrm{mV}$ vs. $\mathrm{Ag} / \mathrm{AgCl}$ at a scan rate of $50 \mathrm{mVs}^{-1}$. Amperometric measurements were performed using PVA-SbQ(ARS)-SPCEs as described in previous studies by author ${ }^{[8,9]}$. Electrodes were polarized at a potential of $+480 \mathrm{mV}$ vs. $\mathrm{Ag} / \mathrm{AgCl}$ in PPB. This was repeated to construct aluminum calibration curves for a range of $\mathrm{Al}(\mathrm{III})$ concentrations from 0 to $5 \mathrm{mM}$ using a fresh PVA-SbQ(ARS)-SPCE for each measurement.

\section{Results and Discussion}

\subsection{Cyclic Voltammetry of Alizarin Red S}

Cyclic voltammograms with bare(PVA-SbQ-SPCEs) and ARS modified electrodes(PVA-SbQ(ARS)-SPCEs) were obtained in $50 \mathrm{mM}$ PPB(pH6.0, $100 \mathrm{mM} \mathrm{KCl}$ ) and a representative example is shown in Fig. 1. Potential sweeping was initiated in an anodic direction from $-0.1 \mathrm{~V}$ in all experiments.

As can be seen in curve B in Fig. 1, no specific oxi-

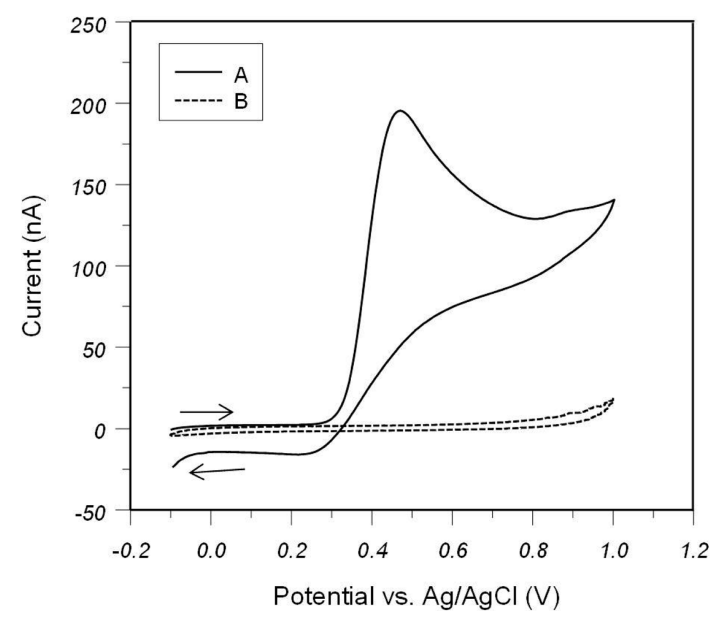

Fig. 1. Cyclic voltammograms for PVA-SbQ(ARS)-SPCEs (A) and PVA-SbQ-SPCEs (B) in $50 \mathrm{mM}$ PPB (pH6.0, $100 \mathrm{mM} \mathrm{KCl).}$ 

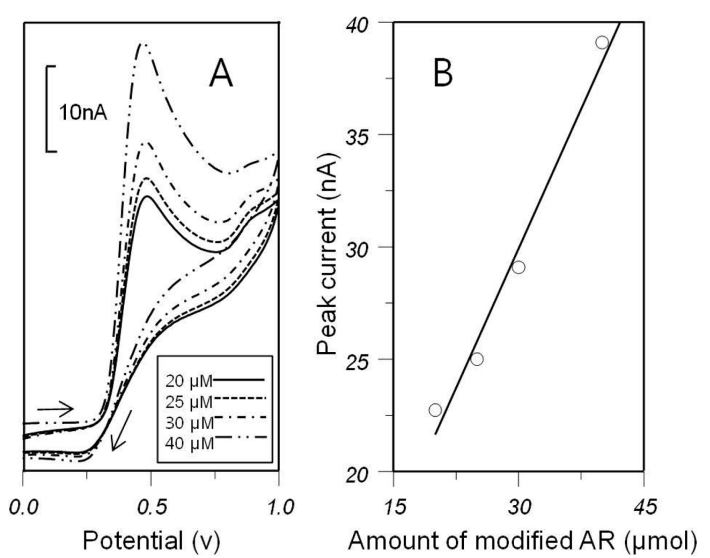

Fig. 2. A: Cyclic voltammograms for PVA-SbQ(ARS)SPCEs in $50 \mathrm{mM} \mathrm{PPB}(\mathrm{pH} 6.0,100 \mathrm{mM} \mathrm{KCl}$,). Experimental conditions; Scan range was from $0.1 \mathrm{~V}$ to $+1.0 \mathrm{~V}$ at a scan rate of $50 \mathrm{mVs}^{-1}$ and scan started at $-0.1 \mathrm{~V}$. Amounts of modified ARS at each electrode were $20,25,30$ and $40 \mu \mathrm{mol}$. B: Plot of peak current vs. amount of modified ARS from voltammograms in A.

dation and reduction current peaks were observed in the absence of modified ARS over the total sweep range of $-0.1 \mathrm{~V}$ to $+1.0 \mathrm{~V}$. In the case of cyclic voltammograms for PVA-SbQ(ARS)-SPCEs, a clear anodic peak was apparent at a potential of $+0.48 \mathrm{~V}$ with an anodic peak current of $190 \mathrm{nA}$ and is shown in curve A in Fig. 1. After sweeping 5 times at potentials between -0.1 and $+1.0 \mathrm{~V}$, the peak current remained practically constant, which indicated the strong and stable modification of ARS on the surface of the electrodes.

Fig. 2 shows examples of cyclic voltammograms for PVA-SbQ(ARS)-SPCEs that were modified with a series of ARS concentrations. The final amounts of ARS modified at each electrode ranged from 20 to $40 \mu \mathrm{mol}$. As can be seen, the peak heights produced were proportional to the amount of ARS on the modified surface.

The voltammetric behavior of ARS is known to be quasi-reversible, showing redox peaks at potentials over the range -0.6 to $-0.8 \mathrm{~V}$ vs. SCE when graphite working electrodes were used ${ }^{[2]}$. In this range of potentials, however, the voltammograms obtained using the electrodes under investigation in this study showed a large cathodic peak and high noise. Although ARS could produce redox peaks at negative potentials, the electro-

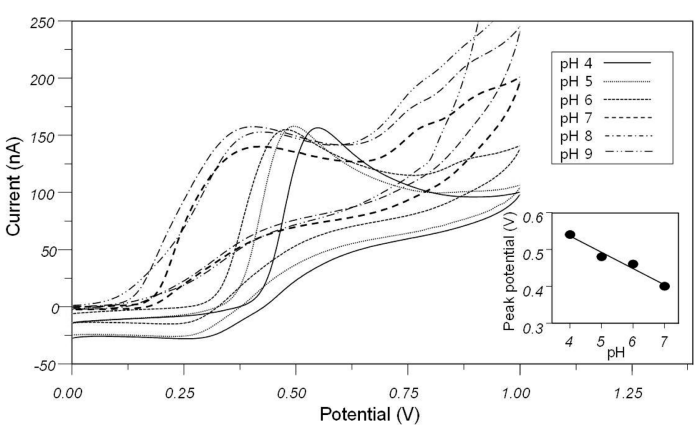

Fig. 3. Cyclic voltammograms for PVA-SbQ(ARS)-SPCEs in $50 \mathrm{mM} \mathrm{PPB}(\mathrm{pH} 4.0,5.0,6.0,7.0,8.0$ and 9.0, $100 \mathrm{mM} \mathrm{KCl}$ ). Inset: linear relationship between peak potential and $\mathrm{pH}$.

chemical behavior would be subject to interference from the reduction of dissolved oxygen ${ }^{[11]}$. This would lead to major irreproducibility problems. As a result of these considerations, therefore, the potential range from -0.1 to $+1.0 \mathrm{~V}$ was used for all cyclic voltammetric experiments.

The cyclic voltammograms for PVA-SbQ(ARS)SPCEs were sensitively dependent on the change of $\mathrm{pH}$. As can be seen in Fig. 3, peak potentials shifted as a function of $\mathrm{pH}$. At higher $\mathrm{pH}$ over 6 , however, the quasi-reversible behavior of ARS was deformed compared with the voltammograms obtained at lower $\mathrm{pH}$. At $\mathrm{pH} 7$ to 9 , the large cathodic picks were produced at potentials higher than $800 \mathrm{mV}$ vs. $\mathrm{Ag} / \mathrm{AgCl}$ and the peaks were broadened. It was, consequently, difficult to determined reproducible peak potentials. Therefore, $\mathrm{pH} 6$ was used as an operating $\mathrm{pH}$ for further voltammetric experiments. The inset in Fig. 3 shows a linear relationship between the peak potentials and $\mathrm{pH}$ from 4 to 7 . The slope for the line was calculated to be; $\Delta \mathrm{E}_{\mathrm{p}} / \Delta \mathrm{pH}=-44 \mathrm{mV} / \mathrm{pH}$.

\subsection{Voltammetric Detection of $\mathrm{Al}(\mathrm{III})$}

In the presence of $\mathrm{Al}(\mathrm{III})$, the change in cyclic voltammograms of PVA-SbQ(ARS)-SPCEs is shown in Fig. 4. As can be seen, the peak potentials are nearly constant while the magnitude of anodic peak current is decreased as a function of the increase in aluminum concentration in solution. The responses of ARS modified electrodes showed a similar peak current decrease with a series of $\mathrm{Al}(\mathrm{III})$ samples measured over the $\mathrm{pH}$ range from 5 to 8 . In recent studies, however, it was 


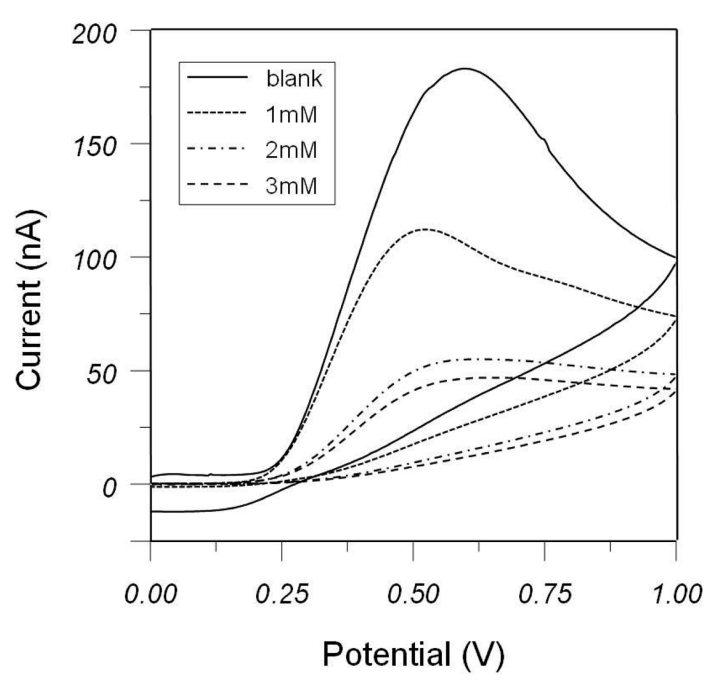

Fig. 4. Cyclic voltammograms for PVA-SbQ(ARS)-SPCEs in $50 \mathrm{mM} \mathrm{PPB}(\mathrm{pH} 6.0,100 \mathrm{mM} \mathrm{KCl})$ with blank, $1.0,2.0$, and $3.0 \mathrm{mM} \mathrm{Al}(\mathrm{III})$.

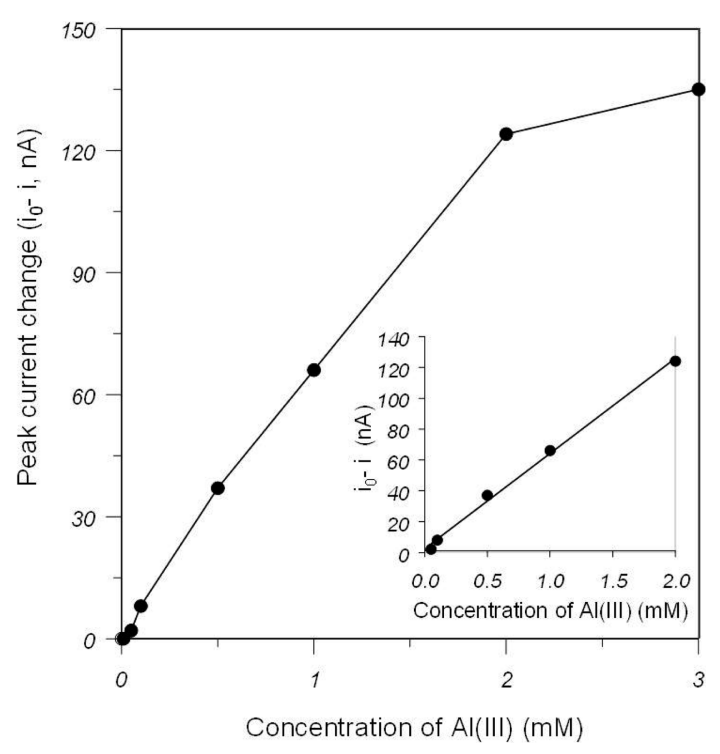

Fig. 5. Calibration curve of anodic peak currents from voltammograms obtained using PVA-SbQ(ARS)SPCEs vs. $\mathrm{Al}(\mathrm{III})$ concentration in $50 \mathrm{mM}$ PPB $(\mathrm{pH} 6.0,100 \mathrm{mM} \mathrm{KCl})$. Inset: linear relationship between peak current and $\mathrm{Al}(\mathrm{III})$ concentration over the range of $0.05-2.0 \mathrm{mM}$.

demonstrated that ARS modified electrodes could be used for the detection of copper in water at $\mathrm{pH}$ 8.0$9.0^{[3,4]}$. Furthermore, at $\mathrm{pH} 6.0$, it was apparent that the anodic peak from the voltammogram had a much smaller peak width compared with the peak at $\mathrm{pH}$ 7.0. Therefore, $\mathrm{pH} 6.0$ was chosen as the operating $\mathrm{pH}$ in all further experiments

In order to obtain data for calibration curves for $\mathrm{Al}(\mathrm{III})$, cyclic voltammograms were obtained with $\mathrm{Al}$ (III) concentrations over the range from 0 to $3 \mathrm{mM}$. Peak currents were determined from the first scan of each voltammogram. Calibration curves for $\mathrm{Al}$ (III) were constructed using the data from the cyclic voltammograms obtained and are shown in Fig. 5. The peak current change $\left(i_{0}-i\right)$ in Fig. 5, represents the differences between peak currents determined by using $\mathrm{Al}(\mathrm{III})$ samples and the peak current obtained from the blank. Although the calibration curve showed a wide range of linearity, approximately from $0.05 \mathrm{mM}$ to $2.0 \mathrm{mM}$ $\mathrm{Al}(\mathrm{III})$ and the sensitivity of the electrodes for $\mathrm{Al}(\mathrm{III})$ was determined to be $0.63 \mu \mathrm{A} \mathrm{mM} \mathrm{cm}$.

\subsection{Amperometric Detection of $\mathrm{Al}(\mathrm{III})$}

Amperometric measurements were performed with Alizarin Red S modified screen-printed carbon electrodes(PVA-SbQ(ARS)-SPCEs) as described Steady baseline currents were observed after 5 minutes $\sim 10$ minutes when the PVA-SbQ(ARS)-SPCEs were polarized at a potential of $+480 \mathrm{mV}$. The steady state current observed was produced by oxidation of ARS, which was modified in the polymer layer on the surface of the electrodes. After addition of a $10 \mu \mathrm{l}$ aliquot of an Al(III) sample into the cell, the color of the PVASbQ(ARS) polymer layer instantly changed from pale yellow to reddish yellow indicating the formation of an ARS-Al(III) complex on the surface of the electrodes.

Because of the strong chelating ability of Alizarin Red S to Al(III), the ARS-Al(III) complex formed was irreversible ${ }^{[12]}$. Therefore, the decrease in current response was recorded and the current changes obtained were used to construct a calibration curve. An unused fresh PVA-SbQ(ARS)-SPCEs was used for each individual measurement. PVA-SbQ(ARS)-SPCEs were calibrated using $\mathrm{Al}(\mathrm{III})$ standard solution and calibration curves for $\mathrm{Al}(\mathrm{III})$ are shown in Fig. 6. Each point represents the mean value of 5 measurements and the error bars represent one standard deviation. The peak current change $\left(i_{0}-i\right)$ in Fig. 6, represents the difference between the current response obtained after addition of an $\mathrm{Al}(\mathrm{III})$ sample and the response of the blank. The detection 


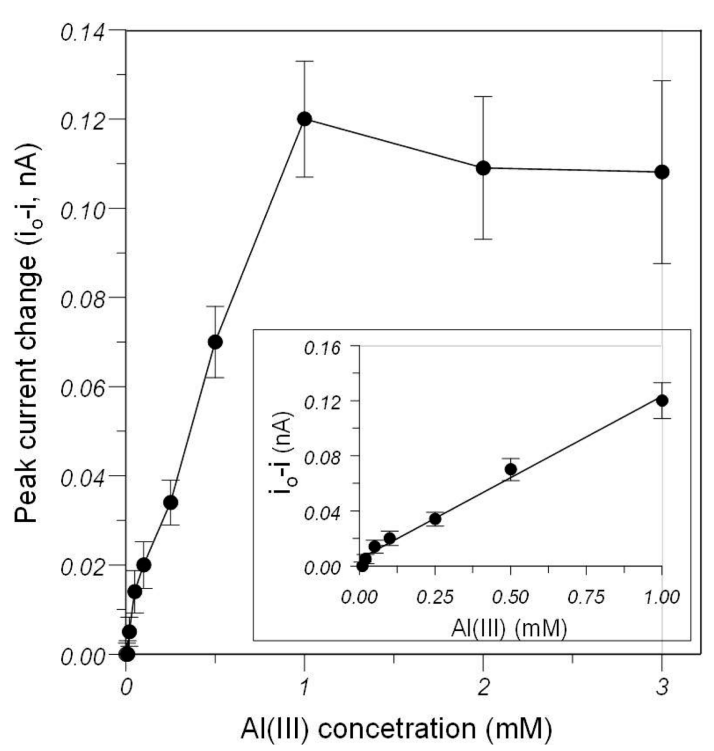

Fig. 6. Calibration curve for $\mathrm{Al}(\mathrm{III})$ using PVA-SbQ (ARS)-SPCEs. Inset: linear relationship between peak current and $\mathrm{Al}(\mathrm{III})$ concentration over the range of $0.05-1.0 \mathrm{mM}$.

$\operatorname{limit}(25 \mu \mathrm{M})$, sensitivity $\left(3.8 \mathrm{nA} \mu \mathrm{M}^{-1} \mathrm{~cm}^{-2}\right)$ and linear range $(25 \mu \mathrm{M}$ to $1 \mathrm{mM})$ of the method were determined using the results obtained. Intra-electrode reproducibility was determined as a coefficient of variation $(\mathrm{CV})$ of less than $14.5 \%$ over the $\mathrm{Al}(\mathrm{III})$ concentration range of $0.1 \mathrm{mM} \sim 0.5 \mathrm{mM}$.

\subsection{Comparison with Alternative Electrochemical $\mathrm{Al}(\mathrm{III})$ Detection Methods}

The suitability of PVA-SbQ(ARS)-SPCEs for Al(III) detection in water samples was investigated in comparison with other methods using CMEs. The results are summarized in Table 1.

It was noted that the anodic peak currents obtained using the methods based on ASV(adsorption stripping voltammetry) in Table 1, were obtained by the reduction or oxidation of chelator-metal complexes that were accumulated on the surface of electrodes prior to application of the stripping potential. However, the system under investigation in this study detects the change in oxidation current produced not from the metallic complexes but from the modified chelator, ARS. Although all the methods summarized in Table 1 based on ASV show a lower detection limit compared with the present
Table 1. Comparison of present sensor system and other electrochemical $\mathrm{Al}(\mathrm{III})$ detection methods

\begin{tabular}{ccccc}
\hline $\begin{array}{c}\text { Chelators } \\
\text { used }\end{array}$ & $\begin{array}{c}\text { Chelator } \\
\text { Modification } \\
\text { Method }\end{array}$ & $\begin{array}{c}\text { Method } \\
\text { based on }\end{array}$ & $\begin{array}{c}\text { Detection } \\
\text { limit } \\
(\mathrm{ppm})\end{array}$ & Ref. \\
\hline $\begin{array}{c}\text { Alizarin } \\
\text { Red }\end{array}$ & $\begin{array}{c}\text { Polymerization } \\
\text { with PVA-SbQ }\end{array}$ & $\begin{array}{c}\text { Ampero- } \\
\text { metry }\end{array}$ & 167 & $\begin{array}{c}\text { Present } \\
\text { system }\end{array}$ \\
\hline $\begin{array}{c}\text { Alizarin } \\
\text { Red }\end{array}$ & Drop coating & ASV & 60 & {$[2]$} \\
\hline $\begin{array}{c}\text { Pyrocatech } \\
\text { ol violet }\end{array}$ & Adsorption & ASV & 6 & {$[11]$} \\
\hline $\begin{array}{c}\text { 8-hydroxy- } \\
\text { quinoline }\end{array}$ & Adsorption & ASV & 4 & {$[12]$} \\
\hline
\end{tabular}

sensor based system, they usually need a longer detection time and a repeatable electrode polishing step at each measurement. Therefore, these differences indicate that the present system is a simpler system because it does not involve an analyte accumulation and an electrode polishing step and the use of the disposable electrodes. Furthermore, because of the additional steps of the ASV based methods, they may not be suitable for the incorporation into a hand held device.

Overall, in order to develop highly sensitive screen printed disposable sensor system for Al(III), the following approaches would be suggested; SPCEs could be modified using PVA-SbQ with chelators that have highly specific and strong chelating abilities to Al(III) such as N,N'-Bis(salicylidene)-1,2-phenylenediamine ${ }^{[5]}$. Another approach would be to incorporate chelators into the screen-printed carbon ink electrode in a manner similar to that described reported previously ${ }^{[13,14]}$. This may be easily achieved by mixing the chelator with the carbon ink prior to printing.

\section{Conclusion}

The work carried out in this study has demonstrated the use of a chelator for the on-site electrochemical determination of aluminum in water resources. Unlike traditional electrochemical detection methods such as ASV, the methods carried out in this work were based upon the measurement of changes in the electrochemical behavior of the chelator upon complexation with $\mathrm{Al}(\mathrm{III})$. The sensor developed in this study showed a detection limit for $\mathrm{Al}(\mathrm{III})$ of $25 \mu \mathrm{M}(167 \mathrm{ppm})$, with a short turnaround time( $15 \mathrm{~min}$ for each measurement). 
The simple screen-printing technique and the effective chelator modification procedure using direct polymerization on electrodes allows inexpensive and disposable amperometric Al(III) sensor fabrication.

\section{Acknowledgements}

This work was supported by the Korea Research Foundation Grant funded by the Korean Government (MOEHRD, Basic Research Promotion Fund)(KRF2007-331- C00184).

\section{References}

[1] D. Compagnone et al., "Electrochemical sensors for determination of metal ions", Sensors and Actuators B-Chemical, vol. 7, pp. 549-552, 1992.

[2] A. Downard et al., "Voltammetric determination of aluminium(III) using chemically modified electrodes", Analytica Chimica Acta, vol. 251, pp. 157163, 1991.

[3] K.-K. Shiu and F.-Y. Song, "Preconcentration and electroanalysis of copper species at electrochemically activated glassy carbon electrodes adsorbed with Alizarin Red S", Electroanalysis, vol. 10, pp. 256-261, 1998.

[4] V. Filho et al., "Surface complexation of copper(II) with alizarin red s adsorbed on a graphite electrode and its possible application in electroanalysis", Electroanaysis, vol. 11, pp. 1130-1136, 1999.

[5] M. Gholivand et al., "A novel Al(III)-selective electrochemical sensor based on N,N'-Bis(salicylidene)1,2-phenylenediamine complexes", Electroanalysis, vol. 18, No. 16, pp. pp. 1620-1626, 2006.

[6] D. Junwei, "Voltammetric determination of aluminum(III) using a reagentless sensor fabricated by sol-gel process", Sensors and Actuators B, vol. 99. pp. 468-473, 2004.

[7] D. Arrigan, "Voltammetric determination of tracemetals and organics after accumulation at modified electrodes", Analyst, vol. 119, pp. 1953-1966, 1996.

[8] S. Chang and D. Park, "Disposable in-field electrochemical potable sensor system for free available chlorine(FAC) detection", J. Kor. Sensors Soc., vol. 16, no. 6, pp. 449-456, 2007.

[9] D. Park et al., "Tri-enzyme modified electrochemical biosensor for paracetamol detection", J. Kor. Sensors Soc., vol.17, no.1, pp. 29-34, 2008.

[10] D. Lee, "Chemical sensor technology", J. Kor. Sensors Soc., vol. 18, no. 1, pp. 1-21, 2009.

[11] D. Vukomanovic et al., "Voltammetric determination of $\mathrm{Al}(\mathrm{III})$ with adsorptive preconcentration of the pyrocatechol violet complex", Canadian Journal of Chemistry, vol. 69, pp. 1418-1426, 1991.

[12] E. Stryjewska and S. Rubel, "Adsorptive stripping voltammetry for determination of trace amounts of aluminium with calmagite", Electroanalysis, vol. 3, pp. 995-998, 1991.

[13] R. Keay et al., "Separation-free electrochemical immunosensors for rapid determination of atrazine", Biosensors and Bioelectronics, vol. 13, pp. 963-970, 1998.

[14] S. Chang et. Al., "Disposable tyrosinase-peroxidase bi-enzyme sensor for amperometric detection of phenols", Biosens. Bioelectr, vol. 17, pp. 10151023, 2002. 


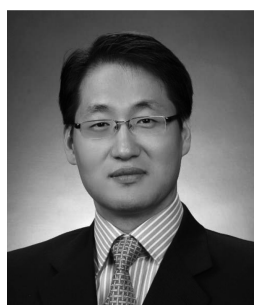

\section{Seung-Cheol Chang}

- Seung-Cheol Chang earned a B.Sc. in Chemistry in 1994 from Dongguk University and received a Ph.D. in Clinical Biochemistry from the University of Newcastle upon Tyne, UK in 2000. From 1999 to 2005, he worked as a Researcher in the Medical School and Institute for Nanoscale Science \& Technology(INSAT) at the University of Newcastle upon Tyne. From Jan. 2006 to Feb. 2007, he worked as a Principle Researcher in the Medical School at Newcastle University. Since Mar. 2007, he has been an Assistant Professor in the Institute for BioPhysio Sensor Technology(IBST), Pusan National University. His research interests are biosensors and diagnostic devices such as cell-based(bio) sensor systems and functionalized microfabricated sensors and arrays based on bioMEMS. 